Relations industrielles

Industrial Relations

\title{
Managers as Consumers of Organizational Behavior: An Historical Perspective on the " Relevance " Debate
}

\section{Larry F. Moore et Craig C. Pinder}

Volume 34, numéro 4, 1979

URI : https://id.erudit.org/iderudit/029016ar

DOI : https://doi.org/10.7202/029016ar

Aller au sommaire du numéro

Éditeur(s)

Département des relations industrielles de l'Université Laval

ISSN

0034-379X (imprimé)

1703-8138 (numérique)

Découvrir la revue

Citer cet article

Moore, L. F. \& Pinder, C. C. (1979). Managers as Consumers of Organizational Behavior: An Historical Perspective on the "Relevance " Debate. Relations industrielles / Industrial Relations, 34(4), 799-809.

https://doi.org/10.7202/029016ar

Tous droits réservés (c) Département des relations industrielles de l'Universite Laval, 1979
Ce document est protégé par la loi sur le droit d'auteur. L'utilisation des services d’Érudit (y compris la reproduction) est assujettie à sa politique d'utilisation que vous pouvez consulter en ligne.

https://apropos.erudit.org/fr/usagers/politique-dutilisation/ 


\title{
Managers as Consumers of Organizational Behavior: An Historical Perspective on the "Relevance" Debate
}

\author{
Larry F. Moore \\ and \\ Craig C. Pinder
}

Professors of business, management, organizational behavior, and kindred academic disciplines are under continual pressure to be practical and "relevant" in both their research and teaching activities. The pressure emanates for the most part from practising managers who have real problems that need solving, as well as from students of business and administration who are preparing themselves for careers devoted to solving such problems after they graduate. Because the academic needs both the manager and the student to justify and underwrite his existence, he often succumbs to this pressure and does his best to bring his thoughts "down from the clouds"' of theory to a level that makes them easily understandable and readily applicable by these two "pressure" groups. In many cases both the practitioner/student and the academic benefit considerably from the exchange because the former receives help for his problems while the latter determines whether his ideas are valid or have any applied utility.

Often, however, the outcome of such exchanges is not so mutually satisfactory, and the premature application of research findings takes place. Usually in such cases the practitioner finds that the theory or tool is inappropriate or invalid for his particular needs, and/or the academic finds that he has made it possible for the manager to institute changes in his organization that have unfortunate, unforeseen consequences for the client system and its employees.

The purpose of this paper is (1) to illustrate that the pressure to be practical is not unique to organizational behavior (O.B.) but may lead to misapplication or undesirable side effects, and (2) to offer suggestions for both academics and practitioners which may lead to more successful implementation of behavioral science findings in organization settings. To begin the argument, we will examine the development of O.B. as an academic discipline, highlighting some striking similarities between it and the early development of medical science. We will attempt to show how these two disciplines have been subjected to similar pressures for application from their respective applied/professional constituent groups. We will then discuss some long and short term costs and benefits to both the manager

* MOORE, L.F. and PINDER, C., Faculty of Commerce and Business Administration, The University of British Columbia. 
and the academic of premature widespread application of organizational behavior insights and theories, and urge caution and conservatism as more is learned about how organizations function and about the organizational processes on which efficiency and effectiveness depend.

\section{SIMILARITIES WITH MEDICAL SCIENCE}

Although its history is much shorter, the development of the field of O.B. closely parallels that of medicine, a field also characterized by pressures for relevance and the early application of its research findings.

\section{Periods of Naive Generality}

A "religio-mystic" era in medicine can be found in the early history of every major civilization. Initially, most medical phenomena were explained in magical terms, until man's empirical knowledge (based on trial and error) finally progressed to a state where he had a degree of control over a few diseases and afflictions. For centuries, paradigm formation in medicine progressed very slowly because of the veneration of ancestral wisdom. For example, in Egypt, 1900 B.C., physicians had begun to specialize, but all cures were revealed by the gods and recorded in secret books kept in medical schools in temples and used only by priests. Strict observance of the directions for a cure was mandatory. Through the use of a number of naively contrived general cures the young field of medicine achieved stability and applicability. Failures were attributed to the will of the gods ${ }^{1}$.

Likewise, during the formative years - from approximately 1900 to 1945 - organizational behavior (in the form of "principles of management") saw considerable application by "progressive" managers even though the scientific basis for the discipline was immature, incomplete, and fraught with untested and invalid assumptions ${ }^{2}$. Nevertheless, as was the case in the early period of medicine, the practitioner's need to tackle important problems overshadowed any concern on the part of researchers and thinkers that the boundary conditions for application were unknown, or that all of the consequences of applications were not predictable.

\section{Periods Assuming Simplistic Causality}

By the twelfth and thirteenth centuries, scientific inquiry began to progress, and medicine entered its second era. Beginning with the medical school at Salerno, doctors started throwing off the blinders of "magicomystical ritual" and began studying diseases first hand while at the same time practising simple therapeutic treatment based on sensible rules of health rather than adhering to witchcraft or religious cures ${ }^{3}$. Unfortunately, their prescriptions often assumed simplistic, overgeneralized causes of il-

1 See MARGOTTA.

2 See STRAUSS, et al.

3 See LEFF and LEFF. 
lness; hence the outcomes were often uncertain. Faddism in practice was rampant during this second phase of medical science; purging, emetics, and bloodletting were widely used to treat various afflictions.

The second phase in the development of O.B., the "Human Relations Era", began with the wide dissemination of the results of the Hawthorne studies in the early 1940's and continued with the participative management movement, lasting until the early 1960's. During this period a new set of "principles" was introduced, this time based on some incredible new discoveries about human behavior at work. Bernard and McGregor supplied the theoretical frameworks while Likert and others added the empirical evidence. There was apparent stability in the field although the new human relations theories did not always agree with the earlier principles laid down by Fayol and his followers. The paradigms used for research during this period were largely unidimensional, perpetuating a search for simplistic relationships, such as that between leadership style and productivity. Many important assumptions made during this period (such as that relating productivity and satisfaction) were not investigated. In short, the Human Relations Era was characterized by simplistic notions of causality, naivety, and considerable faddism, similar to that which had characterized medicine during its second phase of development.

\section{Periods of Explosive Discovery}

The third major phase in the development of medical science was led by the chemist, Pasteur. His discovery that living organisms are the causes of many diseases added new dimensions to medical science. Medical researchers had spent hundreds of years building up a reasonably accurate picture of the frame and structure of the human being, but with the intimate study of living matter (biology), it became possible for medicine to leap ahead to explore the relation between chemical changes and the body's functioning. This period of explosive discovery led to the development of vaccines, recommendations for disease control through refrigeration, sewagedisposal and water purification systems, $\mathrm{x}$-ray technology, anesthesia, and psychoanalytic psychiatry. By no means were all of these advances accepted for application immediately, and for many years it seemed the more biologists and physiologists learned, the more they found there was to learn about the intricate workings of the body. However, there remained much pressure for the application of medical science, leading often to an uncertain regard for quality. Rising concern over inadequately trained doctors and poor medical practice following a Carnegie Foundation study led to a drastic reorganization of medical schools by $1930^{4}$.

In parallel, a period of explosive discovery in organizational behavior was heralded by the emergence of new empirical evidence that contradicted many of the simple tenets and beliefs of the human relations period. Many erstwhile simplistic models about people in organizations (such as the effects of participation on satisfaction and performance) were challenged as academics began to question assumptions about the direction of causality

\footnotetext{
4 See KNOWLES.
} 
between variables of interest. By the mid-1960's, industrial psychologists began to recognize the importance of interdisciplinary analysis. Social scientists moved into schools of business and administration and proceeded to replace the traditional, functionalistic, applications-oriented study of management with an orientation toward intellectual controversy and the pursuit of more complex relationships among variables in organizations. The cumulative effect of these changes was to infuse O.B. with an unstable and admittedly incomplete theoretical grounding, with a clegree of methodological sophistication not generally shared by managers in organizations, and with only a secondary concern for immediate application of research findings. On the surface, this third period held the greatest potential vulnerability for O.B. In substitution for principles and generalizations, the field had little to offer practitioners and students except questions, confusion, and controversies. On the other hand, this period brought intense new intellectual excitement and challenge for scholars in the field.

\section{The Recognition of Human Complexity}

Recently there have been signs that medicine has entered a fourth phase, in which it is increasingly recognized that medicine does not stand alone. Medical problems such as heart disease have been linked to social problems. The link between mental and physical health is finally being rigorously explored. As a profession, medicine has developed complex dependencies and ties with legal and political systems. This new era of complexity will require integrative approaches and the development of increasingly more specialization, at least in medical research.

In the 1970's, organizational behavior appears to have entered a similar new phase in its development - call it the "Organizational Complexity Era" - in which the need to recognize interrelationships and interdependencies is emphasized in the search for more accurate and complete understanding of organizational systems. As in medicine, the range of variables now thought to influence organizational behavior extends far beyond the traditional domain of psychologists and sociologists, and includes phenomena usually studied by economists, political scientists, mathematicians, and philosophers. Frequent observances of unforeseen or theoretically unexplainable side-effects have finally caused students of organization to become more aware of the fallability of their models and the complexity of the variables influencing organizational phenomena ${ }^{5}$

Despite instances of change, uncertainty, and error (e.g. the thalidomide fiasco of the early 1960's) the science of medicine is under as much pressure as ever to supply effective treatments for cancer, heart disease and other killers. Similarly, organizational scientists are witnessing increased pressures to apply their knowledge to organizational issues such as employee malaise, conflict, structure and design, communication and other problems. Accompanying this pressure is a revived emphasis in college textbooks, on the management of organizational behavior ${ }^{6}$.

5 See LUTHANS and STEWARD and LONGENECKER and PRINGLE.

6 See ALBANESE, GLUECK, and LORSCH et al. 
In short, organizational behaviorists have witnessed periods of pressure from managers to become relevant and practical. These periods are neither unique to O.B. nor are they likely to cease. The press of real problems will continue as before or increase as scarcity becomes a common norm for organizations and as managers cast about for help ${ }^{7}$. Can organization scientists help organization managers?

\section{"IT ALL DEPENDS"}

A study of the literature that appears under the general rubric "organizational behavior" reveals that the field has made considerable progress since its inception. But a second examination of this literature reveals the increasing complexity of the models academics have developed to understand and explain organizational phenomena. The complexity is easily understood, however, when one considers the complexity of the phenomena the field attempts to study. Therefore, it is not surprising that academics in O.B. are forced to reply "it depends" increasingly often when they are confronted point blank with questions from managers who need theoretic insight and advice to help solve their problems. Naturally, it is more desirable to develop simple theories than complex theories because simple theories are generally easier to understand, remember, and apply. But the increasing complexity of the research and theory found in the O.B. literature indicates that simplistic prescriptions for organizational and personnel management problems are increasingly less justified.

When a scientist claims that the appropriate solution to a managerial problem "depends" on a number of factors, it behooves someone to demonstrate that the contingent advice can be justified, and that the contingencies spelled out as necessary or sufficient before application can proceed are stable and somewhat universal. If these contingencies are found to vary so much that the prescription must be entirely unique for every managerial problem, the "science" becomes useless and application of its principles less warranted. In other words, sufficient supportive research must be conducted on a sufficiently large number of organizations before the scientist can justify writing prescriptions for the manager. Prescriptions written before these conditions are met constitute what we call cases of "premature" application. Examples of premature application familiar to most personnel and organizational managers would include the installation of many MBO programs, job enrichment changeovers, and many so-called "human relations" treatments. The demise of so many of these programs because of the fact that the appropriate conditions for their installation were not met justifies our charge that these applications were premature. Years after the early commercial application of these techniques, managers and academics are now finally coming up with the knowledge of what successful application of them "depends" upon. Just how much O.B. science is now ready for widespread commercial application? 
One of the authors has argued elsewhere that the widespread commercial application of much of the extant knowledge of employee motivation is probably premature at present ${ }^{8}$. It would follow from that argument that many current theories of applied leadership are equally suspect, since the best of them (such as the "path-goal" models) are rooted in motivation theory, and all of them have implications for employee motivation. Of those theories that seem to work reasonably well (such as goals setting and operant theory), comparatively little is known about why they work.

At the level of group process, social psychologists still seem unsure of the conditions under which groups make riskier decisions than individuals, and in the cases when they do so, why they do so. Another example is found in the fascinating phenomenon called "groupthink". It appears that a certain amount of intra-group cohesiveness is necessary for effective, rational decision making, but not too much ${ }^{9}$. Exactly how much cohesiveness is desirable is not yet known.

It is critical that the reader understand that we do not mean to denigrate the efforts of any of our fellow academics and researchers. The phenomena they are studying are complex, so simple representations of them will probably never be justified. By the same token however, simplistic prescriptions based on these models are not justified either (not yet, at least).

Consider the concepts of organizational structure, technology, and environment, and how they are interrelated. Early research concluded that structure is contingent upon the diversity of the environments (or subenvironments") faced by an organization, ${ }^{10}$ but subsequent research has challenged this hypothesis, claiming that the scaling developed by the early researchers to measure environment is probably inappropriate ${ }^{11}$. The very complexity of the environment concept itself has resulted in a recent taxonomy featuring 64 possible types! 12

It makes good sense that the appropriate structure for an organization should relate somehow to the type of work flow that the organization features and the sort of environment it faces. Moreover, the exact nature of the relationships may in fact be like the ones suggested in the pioneer works of Woodward and Lawrence and Lorsch, in some cases. The trick lies in reliably determining which cases, and the task of future research will be to perform that trick. In the meantime the academic who is honest and sticks to his data on the subject can only advise managers of the state of the science, making the client aware of all of the "if's, and's, and but's" that are necessary, and promise no miracle solutions to the manager's problems. Simultaneously, academe must continue to generate resources to test these theories, expanding on their complexity as needed, so as to ultimately pro-

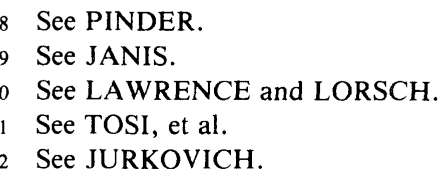


vide more confidence in the prescriptions made. (Note too that ultimately this research will have to be conducted in real organizations for the final validation of the theories.)

In brief, our point is that O.B. is a science with increasingly complex theories: complex because of the complexity of the phenomena it studies. The more that research is conducted to replicate attractive, simplistic early findings, the more it is found that the results of these studies are limited by various circumstances, such that prescriptions based on the theory are subsequently limited and tempered by comments like "it depends"'. Consequently, prudent O.B. scholars and researchers as well as managers must be patient and not expect too much unjustified simplicity too soon in the development and application of O.B. More complex contingency theories ${ }^{13}$ and/or the development of many more middle-range theories ${ }^{14}$ seem indicated.

\section{IMPLICATIONS FOR THE ACADEMIC}

Presumably aware of the current state of the science, Rimler, an academic, has recently re-opened the issue of relevance ${ }^{15}$. In a cute sort of futuristic retrospective on the demise of "management", Rimler describes how the current pre-occupation in the field with mathematics, psychology, and "trivia" lead to the death of the field. Mostly, though, Rimler blames the lack of "relevance" in the work of the field's thinkers.

Earlier it was suggested that while one may feel uneasy over the widespread commercial application of many O.B. concepts and theories, controlled application is a necessary condition for the field to advance. Let's return to that issue. Writing primarily for academic psychologists, Garner has recently provided some useful insight for the resolution in the relevance issue. According to Garner: ${ }^{16}$
"...the quality of the basic research is improved by communication bet- ween the basic research scientist and the people who have problems to solve. Thus, for scientists to engage in goal-oriented research, research aimed at solving problems already known to exist, is both to perform a service to society and to improve the quality of the basic research itself ( $p$. 945)."

Few persons on either side of the relevance debate would disagree with Garner's statement, but as suggested earlier, the essence of the debate hinges on the issue of timing. Obviously, a number of problems can arise when the practitioner is sold a bill of goods based on the latest theories, only to discover a few years later that things have changed, the theory is invalid, or the tools he has been using are, at least, obsolete, or at worst, harmful.

13 See LUTHANS and STEWART.

14 See BEHLING.

15 See RIMLER.

16 See GARNER. 
With regard to Rimler's attack on the academic's preoccupation with "trivia", we believe that the cumulative value of much of what is deemed to be trivial by some critics lies in our ability to refine our theoretical work to the point where it can be characterized as externally valid before making it available for widespread application. In short, whereas Rimler sees a preoccupation with apparent trivia as antithetical to relevance, we believe that such refinement is necessary for the eventual application of theory by practitioners.

\section{Toward a Resolution of the Issue of Application}

The question remains: How can Garner's symbiotic relationship benefitting both the theoretician and the practitioner by pursued while at the same time preventing the problem of premature application mentioned earlier. One proposal made by Pinder is to develop a code of ethics that would encourage controlled application for the sake of external validation and theory development, while simultaneously discouraging the widespread commercial application of tentative, adolescent theory ${ }^{17}$.

A second suggestion concerns the teaching of MBA's and students of commerce. Rather than fostering the conclusion that O.B. has little to offer, the foregoing analysis indicates that students must be impressed with the complexity and pervasiveness of personnel and organizational problems and then exposed to considerable training and education in O.B., so that naive, simplistic models of organizations and organizational behavior are dissipated. Thus the student may be prepared to accept the complexity of multidimensional theories and statements of "it depends". Adept handling of contingencies grows out of sound diagnosis grounded in appropriate and well tested analytical models. Moreover, tomorrow's managers must be trained to protect themselves from the dangers of premature application as practiced by consultants and academics who would sell their half-bak ideas ${ }^{18}$.

House's approach to the training of managers in the context of the pressure for relevance speaks to this point ${ }^{19}$. House argues that professors of management should concentrate on teaching students how to think analytically and critically for themselves, rather than teaching thern specific knowledge content that will likely become out of data after a short while. Professors should practice teaching what Meehl has called "Second Order Relevance": ${ }^{20}$ a focus on general theoretical understanding of phenomena rather than a focus on specific, immediate short-term problems faced by the student/practitioner. Further, House argues that students are better served when they are impressed with the tentative nature of the theory in O.B. than when they are left with the belief that the theory to which they are exposed is final, irrefutable truth.

17 See PINDER.

18 See MOORE and PINDER.

19 See HOUSE.

20 See MEEHL. 
This style is likely to be less popular than the "hands on" approach often demanded and employed in many business schools. Students want to see the immediate applicability of the things we teach them, in the same way thant many client/practitioners prefer simplistic, immediate solutions to their organizational problems. House argues that the academic's goal should be to teach students techniques and solutions for problem solving using current theory, but also to assure that they understand that the theory, by its very nature, may not be "Truth", that it will be subject to change depending upon its fate in further research and its continued ability to predict, understand, and explain phenomena. So students should be taught the presently available theories, techniques and analytical methods, but taught first how to assess the new, unforeseen theory that is likely to develop soon after they leave school. Otherwise, the student is provided with an education limited in both its present flexibility and its likely "relevance" in the future. The authors have described this teaching strategy elsewhere in more detail ${ }^{21}$.

Finally, it is suggested that, in addition to the controls inherent in personnel legislation currently being implemented in the U.S., methods for the licensing and accreditation of personnel managers and others directly responsible for managing human resources should be further developed. The American Society for Personnel Administrators has a certification program which may constitute a step in this direction. In addition, the Academy of Management might be charged with establishing and overseeing the maintenance of minimum standards of training and conduct, leading to the awarding of a certificate to practice. Practitioners so licensed could, apart from demonstrating the minimum required competence levels, be required to observe a code of ethics established by the Academy and risk the loss of accreditation for transgressions against the code. Simultaneously, or after the establishment of the accreditation process, the Academy could proceed to seek the creation and passage of legal statutes which would protect the "consumer" from acts of premature application or other practises not meeting minimum standards of ethics.

\section{IMPLICATIONS FOR THE PRACTITIONER}

The foregoing analysis also contains number of important implications for the practising manager.

First, upon reading journals and textbooks in O.B. for answers to managerial problems, managers should be skeptical of simplistic solutions. Furthermore, managers should be suspicious when academics or consultants provide "easy" solutions or "canned" programs. As argued above, the vast research in O.B. is revealing that simple two and three factor models of the world are usually over-simplifications of reality. A corollary to this point, therefore, is that the manager must develop a patience for statements of the "it all depends" variety, and an appreciation for the contingency and middle range approaches to problem solving. 
Second, realizing that O.B. is a science that presently is undergoing considerable internal conflict among its adherents, the manager must be prepared to accept the likelihood that the theories available today are subject to change as research uncovers new boundary conditions, contingency variables, and answers to what "it all depends" upon.

A third implication is that the prudent manager must learn to consume new theories and techniques wisely, when they are developed. For example, as a practising manager contemplating new theories and techniques, one should pay particular attention to the following types of issues: Has the new concept been substantiated, several times, by rigorous research? Has the technique or concept proved successful in other similar organizations? Are, the effects of the technique lasting, or do they wash out over time? Is the management system prepared to grant the new technique sufficient time and other resources necessary to constitute a fair test of its effectiveness? Are some aspects of the technique or concept of greater relevance to the organization than others, and what are the risks of a partial application? What might be some of the human and financial costs and side effects of application? Do the associated benefits justify the costs? Is the concept intuitively understandable and salable to line personnel, since acceptance of new techniques is usually necessary successful application?

\section{A FINAL NOTE}

In spite of the critical review presented here, there is considerable evidence that behavioral science discoveries have led to the solution of many critical personnel and organizational problems and to improved management practise. Furthermore, the developing field of organizational behavior has much in common with medicine; both fields are becoming increasingly complex and both face continuing pressures for applied solutions, sometimes leading to short run expediency at the expense of careful, thorough scientific investigation. In the future, contributions by behavioral science to management will be more complex than in the past, as academics search for the contingency variables that moderate organizational relationships and as techniques and models are developed, tested, and made available for applications. As astute consumers even greater amounts of time and attention will need to be invested by managers in order to keep abreast of new insights about organizations and to derive the benefits behavioral science will have to offer.

\section{REFERENCES}

ALBANESE, R., Managing: Toward Accountability and Performance. Homewood, Ill., Irwin, 1978.

BEHLING, O., "Some Problems in the Philosophy of Science of Organizations", Academy of Management Review, vol. 3, no. 2, 1978, pp. 193-201.

GARNER, W.R., "The Acquisition and Application of Knowledge: A Symbiotic Relationship", American Psychologist, vol. 27, 1972, pp. 491-946. 
GLUECK, W.F., Management, Hinsdale, Ill., Dryden Press, 1977.

HOUSE, R.H., "The Quest for Relevance in Management Education: Some Second Thoughts and Undesired Consequences", Academy of Management Journal, vol. 18, no. 2, 1972, pp. 323-333.

JANIS, I., Victims of Groupthink, Boston, Houghton Mifflin Co., 1972.

JURKOVICH, R., "A Case Typology of Organizational Environments", Administrative Science Quarterly, vol. 19, no. 3, 1974, pp. 380-394.

KNOWLES, J.H., "The Struggle to Stay Healthy", Time, August 9, 1976, pp. 32-34.

LAWRENCE, P., and LORSCH, J., Organization and Environment, Homewood, Ill., Richard D. Irwin, 1969.

LEFF, S., and LEFF, V., From Witchcraft to World Health, New York, MacMillan, 1957.

LONGENECKER, J.G., and PRINGLE, C.D., "The Illusion of Contingency Theory as General Theory", Academy of Management Review, vol. 3, no. 3, 1978, pp. 679-683.

LORSCH, J.W., BAUGHMAN, J.P., PEECE, J., and MINTZBERG, H., Understanding Management, New York, Harper and Row, 1978.

LUTHANS, F., and STEWART, T.I., “A General Contingency Theory of Management", Academy of Management Review, vol. 2, no. 2, 1977, pp. 181-195.

MARGOTTA, R., An Illustrated History of Medicine, Feltham, Middlesex, Hamlin, 1968.

MEEHL, P., "Second Order Relevance”, American Psychologist, vol. 27, 1972, pp. 932-940.

MOORE, L.F., and PINDER, C.C., "Preparing Students as Consumers of Organizational Behavior: A Call for More Emphasis on Theory", Exchange, vol. III, no. 2, 1978, pp. 20-23.

PINDER, C.C., "Concerning the Premature Application of Human Motivation Theories in Organizational Settings", Academy of Management Review, vol. 2, no. 3, 1977, pp. pp. 384-397.

RIMLER, G.W., “The Death of Management", Academy of Management Review, vol. 1, no. 2, 1976, pp. 126-128.

SCOTT, W.G., "Organization Theory: A Reassessment", Academy of Management Journal, vol. 17 , no. 2 , 1974, pp. 242-254.

STRAUSS, G., MILES, R.E., SNOW, C.C., and TANNENBAUM, A.S. (Eds.), Organizational Behavior: Research and Issues, Madison, Wisconsin, Industrial Relations Research Association, 1974.

TOSI, H. et al., "On the Measurement of the Environment: An Assessment of Lawrence and Lorsch Environmental Uncertainty Subscales", Administrative Science Quarterly, vol. 18 , no. 1,1973 , pp. $27-36$. 